\title{
Spinal Intramedullary Lipoma: A Rare Cause of Rapidly Progressive Quadriparesis
}

Bhawna Sharma*, Tarun Mathur, Raghavendra BS and Rahul Jain

Department of Neurology, SMS Medical College Hospital, Jaipur, Rajasthan, India

\begin{abstract}
Spinal intramedullary lipoma is rare accounting for $1 \%$ of all spinal tumours with usual location in the cervicothoracic region and usually associated with spinal dysraphism. These tumours usually have a slowly progressive indolent course. Our patient a 19 year young male presented with 2 months history of neck pain and acute onset rapidly progressive spastic quadriparesis with sensory level at T4. He did not have spinal dysgraphism. MR spine revealed intramedullary lesions extending from cervicomedullary junction to upper dorsal cord which was hyperintense on T1 and T2 weighted images. Patient was subsequently operated and histopathology of the resected mass showed well circumscribed lesion composed of mature adipose tissue suggestive of lipoma.
\end{abstract}

Keywords: Lipoma; Intramedullary lesions; Spinal dysraphism

\section{Introduction}

Spinal intramedullary lipoma is a rare lesion accounting for $1 \%$ of all spinal masses and $2 \%$ of intramedullary tumours [1]. These lesions are commonly associated with spinal dysraphism [2]. The usual location of spinal lipoma is in the cervico-thoracic region [3]. Spinal intramedullary lipomas without spinal dysraphism are very rare and present in only $1 \%$ of patients $[1,2]$. Though CO2 laser and sonographic aspiration are known to reduce intraoperative damage to the cord and recommended prophylactic intervention in selected asymptomatic patients [4], treatment of intramedullary lipoma is controversial and surgical decompression is indicated for symptomatic lipomas [1]. Surgical intervention in symptomatic patients may lead to significant residual disability [4].

\section{Case Report}

A 19 year old otherwise healthy male presented with 2 months history of acute onset progressive weakness and stiffness in all the four limbs, to begin with lower limbs followed by upper limbs, with history of neck pain without any radiation. He had numbness below the level of chest and there was no history of bladder and bowel involvement. There was no history of trauma or any recurrent episodes of similar illness in the past and family history was negative.

On examination higher mental functions, speech and cranial nerve functions were normal. Motor system examination revealed power of grade 3/5 in both lower limbs and 4/5 in upper limbs, proximally as well as distally. Muscle tone was increased in all 4 limbs. Sensory examination revealed sensory loss below the level of T4 for all the modalities. Deep tendon reflexes of the lower limbs were brisk and plantars were extensor bilaterally. Local examination of the spine did not show any evidence of spinal dysraphism.

On investigating his spinal MRI revealed intradural intramedullary mass which was extending from cervico-medullary junction (C1) to upper dorsal spine (T8). The lesion was hyperintense on both T1 and T2 sequences (Figure 1). The lipomatous nature of lesion was confirmed by total signal suppression on fat suppression sequence. This mass occupied nearly the full diameter of the spinal cord.

Neurosurgery consultation was obtained and he was electively operated under general anaesthesia. Following C1 to T8 laminectomy,

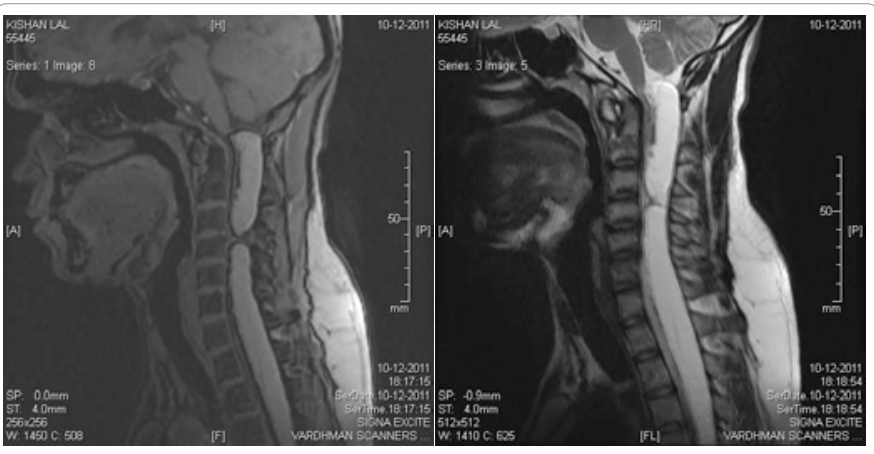

Figure 1: Investigation of spinal MRI intradural intramedullary mass.

dura was opened and midline myelotomy was done. Neurosurgeon confirmed the Intramedullary location of lipoma intraoperatively where tumour was infiltrating the cord tissue. Tumour was resected and sent for biopsy. Histopathology of the resected mass showed well circumscribed lesion composed of mature adipose tissue consistent with lipoma.

At one month follow up there was no change in neurological status of patient. However, patient later lost to follow up and post-operative imaging could not be done.

\section{Discussion}

Intramedullary lipomas are rare consisting of $2 \%$ of all intramedullary tumours and usually associated with spinal dysraphism (upto 99\%) [1]. However, intramedullary lipomas without spinal dysraphism are still more rare and present only in $1 \%$ of patients [2]. In

*Corresponding author: Bhawna sharma, Department of Neurology, SMS Medical College Hospital, Jaipur, Rajasthan, India, E-mail: drbhawnasharma123@ gmail.com

Received September 13, 2012; Accepted November 19, 2012; Published November 21, 2012

Citation: Sharma B, Mathur T, Raghavendra BS, Jain R (2012) Spinal Intramedullary Lipoma: A Rare Cause of Rapidly Progressive Quadriparesis. J Neurol Neurophysiol 3: 139. doi:10.4172/2155-9562.1000139

Copyright: ( 92012 Sharma B, et al. This is an open-access article distributed under the terms of the Creative Commons Attribution License, which permits unrestricted use, distribution, and reproduction in any medium, provided the original author and source are credited. 
Citation: Sharma B, Mathur T, Raghavendra BS, Jain R (2012) Spinal Intramedullary Lipoma: A Rare Cause of Rapidly Progressive Quadriparesis. J Neurol Neurophysiol 3: 139. doi:10.4172/2155-9562.1000139

our patient also intramedullary lipoma was not associated with spinal dysraphism.

The pathogenesis of intramedullary lipomas remains unclear. The location, age of onset, and close association with midline anomalies, are suggestive of a maldevelopment process. It is believed to be an embryologic inclusion of misplaced cell types during neural tube closure suggestive of a hemartomatous origin [5]. Histological, intramedullary lipomas consist of mature fat cells with intervening collagen fibers, and admixed nerve bundles are often located at the periphery, suggestive of secondary entrapment of adjacent nerve roots [5].

Patients with intramedullary lipomas usually present with a slow, indolent, progressive deterioration of neurologic function. Ascending spastic paralysis of one or more limbs is the most frequent presenting symptom. Sensory disturbances in the form of nonradiating pain, urinary incontinence, ataxia, and signs of dorsal column impairment can be present and may exceed the motor symptoms [5]. Patient usually presents with long history of disability followed by rapid progression [6]. Contrary to that, our patient presented with 2 months history of rapidly progressive spastic quadriparesis with definite sensory level without sphincter involvement which is uncommon.

MR imaging is the imaging modality of choice and typically shows a hyperintense lesions on both T1 and T2 weighted sequences [7] as in our patient. Intramedullary lipomas are usually located dorsally, and cervico-thoracic region is most commonly involved [3]. In our patient though location of mass was in cervicothoracic region, it was quite extensive and extending from cervicomedullary junction to upper dorsal cord.
Though CO2 laser and sonographic aspiration is recommended treatment [4], it was not done in our patient because of lack of facility and moreover, they are mainly used as prophylactic measures in asymptomatic patients. Surgical intervention was done in our patient as mentioned previously.

To conclude our patient is rare case of intramedullary lipoma without spinal dysraphism who presented with rapidly progressive spastic paraparesis without sphincter involvement which is again an uncommon entity.

\section{References}

1. Dyck $P$ (1992) Intramedullary lipoma. Diagnosis and treatment. Spine (Phila Pa 1976) 17: 979-981.

2. Corr P, Beningfield SJ (1989) Magnetic resonance imaging of an intradural spinal lipoma: a case report. Clin Radiol 40: 216-218.

3. Naidich TP, Zimmerman RA, MCLone DG, Raybaud CA, Altman NR, et al (1996). Congenital spinal anomalies.In:Atlas SW,editor.Magnetic resonance imaging of the brain and spine. Philadelphia:Lippincott-Raven: 1288-1290.

4. McLone DG, Naidich TP (1986) Laser resection of fifty spinal lipomas. Neurosurgery 18: 611-615.

5. Ammerman BJ, Henry JM, De Girolami U, Earle KM (1976) Intradural lipomas of the spinal cord. A clinicopathological correlation. J Neurosurg 44: 331-336.

6. Lee M, Rezai AR, Abbott R, Coelho DH, Epstein FJ (1995) Intramedullary spinal cord lipomas. J Neurosurg 82: 394-400.

7. Lee RR (2000) MR imaging of intradural tumors of the cervical spine. Magn Reson Imaging Clin N Am 8: 529-540. 